\title{
PSYCHOMETRIC CHARACTERISTICS OF THE MACEDONIAN VERSION OF CLINICAL ASSESSMENT INTERVIEW FOR NEGATIVE SYMPTOMS (CAINS)
}

\author{
Biljana Blaževska Stoilkovska ${ }^{1}$, Stojan Bajraktarov ${ }^{2}$, Silvana Markovska Simoska ${ }^{3}$, Miloš Milutinović ${ }^{2}$ \\ Ljubiša Novotni ${ }^{2}$, Slavica Arsova ${ }^{2}$, Gabriela Novotni ${ }^{4}$, Valentina Čalovska Samardziska ${ }^{2}$, \\ Sonja Delova ${ }^{5}$, Antoni Novotni ${ }^{2} \&$ Nikolina Jovanović ${ }^{6}$ \\ ${ }^{I}$ Department of Psychology, Faculty of Philosophy, Ss. Cyril in Methodius University in Skopje, Skopje, R. North Macedonia \\ ${ }^{2}$ University Clinic of Psychiatry, Ss. Cyril in Methodius University in Skopje, Skopje, R. North Macedonia \\ ${ }^{3}$ Academy of Sciences and Arts of North Macedonia, Skopje, R. North Macedonia \\ ${ }^{4}$ University Clinic of Neurology, Ss. Cyril in Methodius University in Skopje, Skopje, R. North Macedonia \\ ${ }^{5}$ Psychiatric Hospital "Skopje", Skopje, R. North Macedonia \\ ${ }^{6}$ Unit for Social and Community Psychiatry, WHO Collaborating Centre for Mental Health Services Development, \\ Bart's and London School of Medicine and Dentistry, Queen Mary University of London, London, UK
}

received: 23.2.2020;

revised: 5.11.2020;

accepted: 5.1 .2021

\section{SUMMARY}

Background: Despite the importance of effective assessment and treatment of negative symptoms among patients with psychosis, no validated instruments are available in the Republic of North Macedonia. The aim of this paper was to explore psychometric properties, namely factorial structure, internal consistency, convergent and discriminant validity of the Clinical Assessment Interview for Negative Symptoms (CAINS).

Subjects and methods: In this cross-sectional study 82 outpatients diagnosed with psychosis (64 with schizophrenia and 18 with bipolar disorder; female $=34$, mean age $=41.05 \pm 10.09$ ) were assessed.

Results: The exploratory factor analysis revealed two factorial structure of the negative symptoms as measured by the CAINS, i.e. 'expression and motivation' and 'pleasure'. Two items aimed to measure motivation for family relations and motivation for work/school activities loaded on the expression factor instead on motivation and pleasure factor which differs from the original version of the CAINS. Convergent validity was proven by positive relationship to negative symptoms as measured by the BPRS. Positive, but weak correlation with BPRS positive symptoms demonstrated its discriminant validity. Internal consistency of overall CAINS scale and its two subscales was very high.

Conclusion: The CAINS can be used to assess negative symptoms in individuals with psychosis in the Macedonian clinical context. Consequently, this work can provide a foundation for further clinical advancement and research of negative symptoms in Macedonian healthcare.

Key words: CAINS - negative symptoms - psychometric properties - psychosis - Macedonian clinical context

\section{INTRODUCTION}

Negative symptoms in patients with psychosis represent diminished emotional expressiveness, as well as, inability or decreased capacity to initiate and to persist in goal-directed activities. Blunted affect, allogia, anhedonia, avolition and asociality are considered as key negative symptoms (Kirkpatrick et al. 2006, Marder \& Galderisi 2017), contributing to decreased motivation, lack of affect, decline in capacity to experience joy, impoverished speech, reduced social contacts and social withdrawal. They are related, but still separate constructs distinctive from cognitive impairment (Marder \& Galderisi 2017). In addition, important issue is to distinguish primary negative symptoms from secondary negative symptoms which could result from medication side-effects, depression, and positive symptoms (Blanchard \& Cohen 2006, Newcomer et al. 1990), such as hallucinations, and delusions (Kirkpatrick 2014) and paranoia (Correll \& Schooler 2020).
The prevalence of negative symptoms is considerably high in patients with schizophrenia (Bobes et al. 2010, Lyne et al. 2012) and lesser, but noticeable in bipolar disorder (Ameen \& Ram 2007). However, both disorders are characterized with similar level of severity in regard to anhedonia, avolition and asociality, and difference on blunted affect and allogia (Strauss et al. 2016).

The influence of negative symptoms on decline in psychosocial functioning among individuals with psychosis has been well documented (e.g. Fervaha et al. 2014, Hunter \& Barry 2012, Mucci et al. 2017). According to Giacco et al. (2012) almost twice as many patients with absent or mild negative symptoms had met a friend in the last week, compared to those with moderate negative symptoms. In addition, negative symptoms can be serious burden for family/caregivers (Provencher \& Mueser 1997).

Negative symptoms continue to pose a huge challenge to clinicians because they are not easy to assess and currently effective treatments are not effective 
(Remington 2016). Therefore, to have psychometrically sound measure of negative symptoms is critically important as this may facilitate advancements in diagnostics and treatment. In that line, CAINS was developed to overcome the first generation measures of negative symptoms and to contribute to better assessment of negative symptoms and consequently to their more effective treatment (Blanchard et al. 2011). The CAINS assesses domains that map the phenomenology of schizophrenia, on the one hand, and emotion, motivation, and affect processing as constructs that have been extensively researched in neurobiology and psychology fields (Barch 2013). The same author had stressed that particular characteristic of the CAINS is the novel distinction that this measure makes between anticipatory components of pleasure and motivation, as well as the experience or consummation of pleasurable activities. As was reported by the authors of the CAINS, this instrument has acceptable reliability and confirmed construct and discriminant validity (Kring et al. 2013).

\section{The aim of the present study}

Despite the importance of effective assessment and treatment of negative symptoms among patients with psychosis, no validated instruments are available in $\mathrm{RN}$ Macedonia. The aim of this study was to explore psychometric properties, namely factorial structure, internal consistency, convergent and discriminant validity of the CAINS. This will provide a foundation for further clinical advancement and research of negative symptoms in Macedonian healthcare.

\section{SUBJECTS AND METHODS}

\section{Study participants and procedure}

The study included 82 outpatients diagnosed with psychotic disorders. Patients eligibility criteria included: primary diagnosis of psychosis or related disorder (ICD10 F20-29, F31) (ICD-10, WHO, 2016), age above 18, currently attending the outpatient clinic, history of at least one psychiatric hospital admission in their lifetime, and capacity and will to provide informed consent. Patients were excluded if having a diagnosis of organic brain disorders and severe cognitive deficits, thus being unable to provide informed consent and reliable information to study instruments.

The data was collected during February-March, 2019 in hospital centers where participants use outpatient mental health care services. They were invited to come in the term suitable for them during the working days. Usually, it was the term before their regular treatment/ examination appointment. The interview/assessment lasted for 30 minutes. All researchers were trained in administering the CAINS and BPRS.
The study was approved by Ethical committee by the Faculty of Medicine, Ss. Cyril and Methodius University in Skopje. All participants provided written informed consent prior to the study.

\section{Measures}

Clinical Assessment Interview for Negative Symptoms (CAINS, Kring et al. 2013) consists of 13 items covering motivation and pleasure in social (4 items), vocational ( 2 items), and recreation ( 3 items) domains, as well as emotion expression and speech (4 items). The items were rated on a scale from 0 to 4 . Higher obtained scores denoted greater impairment. Patients' reports of experienced motivation, interest and emotion, as well as reports of their actual engagement in relevant social (family, romantic and friend relationships), vocational (work/school), and recreational activities were used as a basis to assess motivation and pleasure (past-week pleasure and expected next-week pleasure). Emotion expression and speech were rated on the basis of observation. The answers given by study participants were evaluated following authors' manual (Blanchard et al. 2012).

Brief Psychiatry Rating Scale (BPRS, Ventura et al. 1993) with 24 items was applied to assess psychiatric symptoms in study participants, but for the purposes of this study only items referring to positive and negative symptoms were used. Based on interview questions and rating guidelines recommended/provided by the authors, all items were rated on a 7 point Likert scale ranging from 1-not present to 7-extremely severe. Higher score indicated more severe symptomatology. Internal consistency of the overall BPRS in this study was $\alpha=0.81$. Cronbach alpha reliability of the BPRS negative symptoms and BPRS positive symptoms was 0.83 and 0.70 , respectively.

\section{Data analysis}

Internal consistency (Cronbach alpha coefficient) was used to test reliability of CAINS. In order to examine its factorial structure, exploratory factor analysis (principal component analysis) was applied, while convergent and discriminant validity were investigated performing correlation analysis (Pearson) between CAINS subscales and BPRS negative and positive symptoms subscales.

\section{RESULTS}

The sample consisted of 82 outpatients with psychosis (64 with schizophrenia and 18 with bipolar disorder) recruited from two psychiatric hospitals in Skopje, the capital of RN Macedonia. Participants' mean age was 41.05 years $(\mathrm{SD}=10.09$, range $24-66)$. Their socio-demographic characteristics are presented in Table 1. 
Table 1. Socio-demographic characteristics of study participants

\begin{tabular}{|c|c|c|}
\hline Socio-demographics & Frequency & Percent \\
\hline \multicolumn{3}{|l|}{ Gender } \\
\hline Female & 34 & 41.5 \\
\hline Male & 48 & 58.5 \\
\hline Total & 82 & 100.0 \\
\hline \multicolumn{3}{|l|}{ Education } \\
\hline Primary education & 12 & 14.6 \\
\hline Secondary education/high school & 47 & 57.3 \\
\hline Higher education (BA diploma) & 21 & 25.6 \\
\hline $\begin{array}{l}\text { Postgraduate/doctoral studies } \\
\text { (MA/PhD diploma) }\end{array}$ & 2 & 2.4 \\
\hline Total & 82 & 100.0 \\
\hline \multicolumn{3}{|l|}{ Employment status } \\
\hline Paid employment & 24 & 29.3 \\
\hline Student & 7 & 8.5 \\
\hline Unemployed & 39 & 47.6 \\
\hline Retired & 9 & 11.0 \\
\hline Other & 3 & 3.7 \\
\hline Total & 82 & 100.0 \\
\hline \multicolumn{3}{|l|}{ Marital status } \\
\hline Single/unmarried & 47 & 57.3 \\
\hline Married & 21 & 25.6 \\
\hline Divorced & 12 & 14.6 \\
\hline Widow/widower & 2 & 2.4 \\
\hline
\end{tabular}

Principal component analysis (PCA) with varimax rotation was applied to assess factor structure of CAINS.

Kiaser-Mayer-Olkin measure was 0.809 indicating very good sampling adequacy. Bartlet's test of sphericity was statistically significant $\left(\chi^{2}(78)=691.06, p<0.001\right)$ demonstrating that correlation coefficients among variables/items were high. Both measures revealed that the data was suitable for PCA.

Eigenvalue greater than 1 was used as a criterion for factor extraction. The result was four factor solution, i.e. motivation and pleasure in social domain, motivation and pleasure in recreation domain, motivation and pleasure in vocational domain and expression factor. As seen, motivation/avolition and pleasure/anhedonia factor in this sample was separated into three groups of symptoms referring to distinct life/social areas. Further, q1 was found to have nearly equal loadings on motivation/pleasure in social activities factor, as well as on expression factor.

Considering that almost all previous studies demonstrated two-factor structure of the CAINS and because motivation and pleasure in work/school domain factor consisted of only 2 items, PCA was rerun using fixed factor criterion with two a priori defined factors. Two extracted factors explained $60.88 \%$ of the variance in the measured construct. Six items loaded on factor 1 accounting for $46.06 \%$ in the variance of the negative symptoms as measured with CAINS. Those were items intended to measure emotion expression and speech in original CAINS version along with $\mathrm{q} 1$ and $\mathrm{q} 5$ that assess motivation for family contacts and motivation for work/school activities, respectively. Factor 2 accounted for $14.82 \%$ in the variance and was represented by seven items measuring motivation for romantic relations and friendship and experienced and anticipated pleasure in social and vocational domain. Rotated component/ factor structure with factor loadings is presented in Table 2 .

Internal consistency of the CAINS total scale was $\alpha=0.90$. Cronbach alpha reliability for Expression factor (Factor 1) and Motivation and pleasure in social activities (Factor 2) was 0.88 and 0.85 , respectively.

Table 3 summarizes mean, standard deviation, and item-total correlation of the CAINS items and obtained factors.

As seen, participants in this study reported moderately severe deficit to anticipate pleasure related to work/school activities. They, also, demonstrated tendency to relatively low level of motivation for friendships

Table 2. Rotated component/factor structure of CAINS and factor loadings

\begin{tabular}{lcc} 
& $\begin{array}{c}\text { Factor 1: } \\
\text { Expression }\end{array}$ & $\begin{array}{c}\text { Factor 2: Motivation and } \\
\text { pleasure in social activities }\end{array}$ \\
\hline Vocal expression & 0.926 & \\
Expressive gestures & 0.889 & \\
Facial expression & 0.887 & 0.804 \\
Quantity of speech & 0.526 & 0.818 \\
Motivation for close family/spouse/partner relationships & 0.517 & 0.792 \\
Motivation for work/school activities & & 0.757 \\
Experienced pleasure from social activities & & 0.747 \\
Expected pleasure from the recreational activities & & 0.719 \\
Motivation for recreational activities & & 0.565 \\
Expected pleasure from the social activities & & 0.448 \\
Experienced pleasure from social activities & & \\
Motivation for romantic relations and friendship & & \\
Expected pleasure from the work/school activities & & \\
\hline
\end{tabular}


Table 3. Descriptive statistics and reliability of CAINS $(\mathrm{N}=78)^{*}$

\begin{tabular}{lcccc}
\multicolumn{1}{c}{ Items } & M & SD & $\begin{array}{c}\text { Item-Total } \\
\text { Correlation }\end{array}$ & $\begin{array}{c}\text { Cronbach's Alpha } \\
\text { if Item Deleted }\end{array}$ \\
\hline f1 expression & 1.26 & 0.960 & & \\
q10 facial expression & 1.44 & 1.295 & 0.833 & 0.828 \\
q11 vocal expression & 1.04 & 1.167 & 0.865 & 0.825 \\
q12 expressive gestures & 1.29 & 1.186 & 0.765 & 0.842 \\
q13 quantity of speech & 0.99 & 1.026 & 0.752 & 0.848 \\
q1 motivation for close family/spouse/partner relationships & 1.03 & 1.032 & 0.479 & 0.885 \\
q5motivation for work/school activities & 1.83 & 1.574 & 0.507 & 0.899 \\
f2 motivation and pleasure in social activities & 1.68 & 0.850 & & \\
q2 motivation for close friendships \& romantic relationships & 1.63 & 1.186 & 0.563 & 0.835 \\
q3 experienced pleasure from social activities & 1.79 & 1.221 & 0.700 & 0.814 \\
q4 expected pleasure from the social activities & 1.96 & 1.145 & 0.663 & 0.820 \\
q6 expected pleasure from the work/school activities & 2.82 & 1.384 & 0.395 & 0.866 \\
q7 motivation for recreational activities & 1.28 & 1.127 & 0.688 & 0.816 \\
q8 expected pleasure from the recreational activities & 1.05 & 1.005 & 0.671 & 0.821 \\
q9 experienced pleasure from social activities & 1.23 & 1.104 & 0.647 & 0.823 \\
Cains total & 1.49 & 0.800 & & \\
\hline
\end{tabular}

"due to missing values on two CAINS items, the analyses were performed on 78 participants

Table 4. Pearson correlation coefficients among the CAINS and BPRS

\begin{tabular}{lcc}
\hline & BPRS_negative & BPRS_positive \\
\hline CAINS total & $0.724^{* *}$ & $0.309^{* *}$ \\
CAINS motivation and pleasure in social activities & $0.502^{* *}$ & $0.250^{* *}$ \\
CAINS expression & $0.791^{* *}$ & $0.300^{* *}$ \\
\hline
\end{tabular}

"statistically significant at $\mathrm{p}<0.05 ; \quad$ statistically significant at $\mathrm{p}<0.01$

and romantic relationships, as well as capacity to experience and anticipate pleasure in those social domains. On the other hand, they, generally, manifested interest to be engaged and to maintain close family relations and had mild deficit in vocational expression and quantity of speech. Inter-item correlation coefficients were high or relatively high in both subscales (factors extracted).

Pearson correlation analysis between the CAINS subscales/factors and BPRS negative symptoms subscale was performed to examine convergent validity (Table 4). Results demonstrated that both CAINS factors, expression and motivation/pleasure were positively and strongly related to BPRS negative symptoms $(\mathrm{r}(\mathrm{df}=76)=0.79, \mathrm{p}<0.001$ and $\mathrm{r}(\mathrm{df}=76)=0.50, \mathrm{p}<0.001$, respectively). Discriminant validity was assessed on the basis of linear correlation coefficients of CAINS factors with BPRS positive symptoms subscale (Table 4). These finding showed that CAINS expression factor and motivation/pleasure factor were considerably weakly associated with BPRS positive symptoms subscale, but still significantly $(\mathrm{r}(\mathrm{df}=76)=0.25, \mathrm{p}<0.05$ and $\mathrm{r}(\mathrm{df}=76)=0.30, \mathrm{p}<0.05$, respectively $)$.

\section{DISCUSSION}

In this study psychometric properties of the CAINS in a sample of outpatients with psychosis in Macedonia were examined. Applied principal component analysis with varimax rotation when eigenvalue $>1$ was used as a criterion for factor extraction revealed four factor solution. The identified factors/dimensions of negative symptoms as measured by the CAINS were emotional expression (F1), motivation for and pleasure in recreational activities (F2) motivation for and pleasure in social contacts (F3) and motivation for and pleasure in work/school activities (F4). This factor solution was similar to that found in a sample of outpatients with schizophrenia in Singapore (Rekhi et al. 2019).

It could be concluded that obtained factor solution reflected tendency amotivation/avolition and anhedonia symptoms, i.e. motivation-pleasure items to form distinct groups on the base of life domains considered. Namely, extracted factors corresponded to the domains in which aforementioned negative symptoms can be present or refer to. In addition, it was noted that Factor 4 consisted of only two items, while item 1 aiming to measure intrinsic motivation and interest in family relations loaded on Factor 1 and Factor 3 almost equally. Its correlation to both, F1 and F2, were close to .50. Even more, screeplot represented two factorial structure of the negative symptoms as measured by the CAINS.

For that reasons, and according to previous study findings (e.g. Engel et al. 2014, Jung et al. 2016, Kring et al. 2013, Valiente-Gómez et al. 2015) PCA was rerun using a priori defined number of factors (two) to be extracted. It should be stressed that q1-motivation and interest for family relations, as well as, frequency of 
actual contacts with family members and q5-motivation and engagement for work activities correlated highly to Expression factor 1 as consistent with study findings in Chinese sample of patients with schizophrenia (Chan et al. 2015). Consequently, factorial structure of the CAINS in this study was shown to be closer/similar to that obtained in Asian culture than in Western culture (e.g. Engel et al. 2014, Valiente-Gómez et al. 2015). The finding that q1 i q5 go along in group of emotional expression items/symptoms might be explained through the notion that family and work are interconnected domains (Greenhouse \& Foley 2007) and both, positive family experiences and positive work experiences can have additive effect on well-being, life satisfaction and happiness (Greenhouse \& Powel 2006) which could be relevant for individuals with psychosis, too. In that line, it might be proposed that involvement in and maintenance of close family relations and work activities that are sources of positive emotional experiences can lead to less impairment in emotional expression.

The content of the Expression factor in this study might be culturally depended. In Macedonian context, collectivistic cultural orientation is relatively highly expressed (Kenig 2006) implying that family members value and tend to hold close bonds characterized with emotions exchange and open emotional expression. Social relations, especially, family, are very important for emotion regulation, as was reviewed by Morris et al. (2007). Furthermore, frequent social contacts in individuals with psychosis would be basis for less emotional withdrawal (Siegrist et al. 2015). Factor 2 CAINS motivation and pleasure in this study was comprised of motivation in friendships and romantic relationships, anticipatory pleasure in work/school activities, as well as interest and pleasure in hobbies and free activities.

It should be noted that, item 1 and item 5 had relatively good correlation with Factor1, however other items referring to expression symptoms loaded on Factor 1 evidently highly. More than $60 \%$ in their variance was accounted by Factor 1. On the other hand, as reported in previous studies q1 and q5 loaded on motivation and pleasure factor, but with low factor loadings (e.g. Kring et al. 2013, Richter et al. 2019). These results indicated that $\mathrm{q} 1$ and $\mathrm{q} 5$ were problematic factors, yet deserved to be further explored (Richter et al. 2019). In addition, more information on the CAINS structure tested using confirmatory factor analysis needs to be provided. For example, model fit indexes in confirmatory factor analysis applied in validation of the Korean version of the CAINS (Jung et al. 2016) are below the recommended values. This implies on possible differences in factors' content and need for further investigation.

In line with the report regarding the reliability (Strauss \& Gold 2016), CAINS total scale and both CAINS Expression subscale and CAINS motivation and pleasure subscale demonstrated excellent internal consistency, but test-retest reliability should be examined in order to confirm the CAINS time stability in Macedonian sample of individuals with psychosis.

The results on convergent validity showed that the overall CAINS measure and its two subscales were strongly and positively associated with BPRS negative symptoms subscale. In particular, CAINS Expression subscale demonstrated very high correlation with this subscale, probably not surprisingly, since both are aiming to assess level of severity of emotional expression. Relationship of CAINS total score, CAINS Expression subscale and CAINS motivation and pleasure to BPRS positive score was higher than expected, yet reflected that negative symptoms as measured by the CAINS can be distinguished from positive symptoms in individuals with psychosis. Similarly, CAINS motivation and pleasure subscale in the initial verion (Forbes et al. 2010), as well as in the final version of the CAINS measure (Kring et al. 2013) demonstrated small and significant positive association with positive symptoms. Similar results regarding discriminant validity of the two CAINS factors and positive symptoms were registered in recent studies. However, this aspect should be further explored (Strauss \& Gold 2016).

The average level of motivation-pleasure symptoms and emotional expression symptoms were similar to previous findings (e.g. Chan et al. 2015, Strauss \& Gold 2016). Results on the level of interest for and engagement in social contacts are in line with existing empirical findings that nearly $50 \%$ of social network is accounted by family members and $26 \%$ by friends (Palumbo et al. 2015), that individuals with psychosis have fewer friends (Giacco et al. 2012) and experience difficulties to engage in romantic relationships (Redmond et al. 2010).

\section{CONCLUSION}

This study showed that the CAINS measure can be used for assessment of the negative symptoms in outpatients with psychosis. Specifically, its factorial structure was very similar to those obtained in another studies, thus confirming that two groups of negative symptoms can be identified/assessed using this measure in a clinical setting. Additional support of this conclusion is its high internal consistency. These results are particularly important since there is no validated measure of negative symptoms in a Macedonian clinical/health care context.

Further, the CAINS can be used as a valid and reliable instrument in research purposes when negative symptoms among individuals with psychosis would be examined. However, its factorial structure using confirmatory factor analysis conducted on a largesr sample needs to be investigated in the future studies. 


\section{Acknowledgements:}

This manuscript was prepared as part of the research project titled Implementation of an effective and costeffective intervention for patients with psychotic disorders in low and middle income countries in South Eastern Europe (IMPULSE) funded by European Commission, Directorate-General Research \& Innovation, Grant agreement number 779334.

\section{Conflict of interest: None to declare.}

\section{Contribution of individual authors:}

Biljana Blaževska Stoilkovska took part in data collection and literature review, performed statistical analyses, interpretation of data and manuscript writing.

Stojan Bajraktarov \& Antoni Novotni recruited and selected participants in the study, organized questionnaires and took part in literature searches.

Silvana Markovska Simoska, Miloš Milutinovic \& Ljubiša Novotni organized and administered questionnaires to the study participants and took part in database preparation.

Slavica Arsova, Valentina Čalovska Samardziska \& Sonja Delova took part in recruitment and selection of the participants in the study.

Gabriela Novotni took part in literature searches.

Nikolina Jovanovic designed the study, and took part in manuscript writing.

All authors drafted the manuscript and approved its final version.

\section{References}

1. Ameen $S \&$ Ram D: Negative symptoms in the remission phase of BPD. Ger J Psychiatry 2007; 10:1-7

2. Barch DM: The CAINS: Theoretical and Practical Advances in the Assessment of Negative Symptoms in Schizophrenia. Am J Psychiatry 2013; 170:133-135[0]

3. Blanchard JJ \& Cohen AS: The Structure of Negative Symptoms Within Schizophrenia: Implications for Assessment. Schizophr Bull 2006; 32:238-45

4. Blanchard JJ, Gur R, Horan WP \& Kring AM: Manual for the Clinical Assessment Interview for Negative Symptoms (CAINS). CANSAS Collaborative Group, 2012

5. Blanchard JJ, Kring AM, Horan WP \& Gur R: Toward the Next Generation of Negative Symptom Assessments: The Collaboration to Advance Negative Symptom Assessment in Schizophrenia. Schizophrenia Bulletin 2011; 37:291-99

6. Bobes $J$, Arango C, Garcia-Garcia M, Rejas $J$ \& CLAMORS Study Collaborative Group: Prevalence of negative symptoms in outpatients with schizophrenia spectrum disorders treated with antipsychotics in routine clinical practice: findings from the CLAMORS study. $J$ Clin Psychiatry 2010; 71:280-6

7. Chan RCKC, Shi C, Simon SY, Lui SSY, Ho KKY, Hung $K S Y$ et al.: Validation of the Chinese version of the
Clinical Assessment Interview for Negative Symptoms (CAINS): a preliminary report. Front Psychol 2015; 6:1-5

8. Correll CU \& Schooler NR: Negative Symptoms in Schizophrenia: A Review and Clinical Guide for Recognition, Assessment, and Treatment. Neuropsychiatr Dis Treat 2020; 16:519-534

9. Engel M, Fritzsche A\& Lincoln TM: Validation of the German version of the Clinical Assessment Interview for Negative Symptoms (CAINS). Psychiatry Res 2014; 220:659-63

10. Fervaha G, Foussias G, Agid $O$ \& Remington G: Impact of primary negative symptoms on functional outcomes in schizophrenia. Eur Psuciatry 2014; 29:449-55

11. Forbes C, Blanchard JJ, Bennet M, Horan WP, Kring $A$ \& Gur R: Initial development and preliminary validation of a new negative symptom measure: The Clinical Assessment Interview for Negative Symptoms (CAINS). Schizophr Res 2010; 124:36-42

12. Giacco D, McCabe R, Kallert T, Lars Hansson L, Fiorillo $A \&$ Priebe S: Friends and Symptom Dimensions in Patients with Psychosis: A Pooled Analysis. Plos One 2012; 11:1-9

13. Greenhouse $J \&$ Foley $S$ : The Intersection of Work and Family Lives. In Gunz H \& Peiperl M (Eds): Handbook of Career Studies, Thousand Oaks, CA: Sage Publications, 2007; 131-152

14. Greenhouse JH \& Powell GN: When work and family are allies: A theory of work family enrichment. Acad Manage Rev 2006; 31:72-92

15. Hunter $R \&$ \&arry $S$ : Negative symptoms and psychosocial functioning in schizophrenia: neglected but important targets for treatment. Eur Psychiatry 2012; 27:432-6

16. Jung S, Woo J, Kim YT \& Sang Gyu Kwak SG: Validation of the Korean-Version of the Clinical Assessment Interview for Negative Symptoms of Schizophrenia (CAINS) J Korean Med Sci 2016; 31:1114-20

17. Kenig N: Hofstedoviot model na dimenzii na kulturata: možnosti za merenje vo grupen $i$ individualen kontekst. (Hofsted model of cultural dimensions: measurement in a group and individual context. Unpublished doctoral dissertation, Faculty of Philosophy in Skopje), 2006

18. Kirkpatrick B, Fenton WS, Carpenter, Jr. WT \& Marder SR: The NIMH-MATRICS Consensus Statement on Negative Symptoms. Schizophr Bull 2006; 32:214-19

19. Kirkpatrick B: Recognizing primary vs secondary negative symptoms and apathy vs expression domains. J Clin Psychiatry 2014; 75:e09

20. Kring AM, Gur RE, Blanchard JJ, Horan WP \& Reise SP: The Clinical Assessment Interview for Negative Symptoms (CAINS): Final Development and Validation. Am. J. Psychiatry 2013; 170:165-72

21. Lyne J, O'Donoghue B, Owens E, Renwick L, Madigan K, Kinsella $A$ et al.: Prevalence of item level negative symptoms in first episode psychosis diagnoses. Schizophr Res 2012; 135:128-33

22. Marder SR \& Galderisi S: The current conceptualization of negative symptoms in schizophrenia. World Psychiatry 2017;16:14-24

23. Morris AS, Silk JS, Steinberg L, Myers SS, Robinson LR: The Role of the Family Context in the Development of Emotion Regulation. Soc Dev 2007; 16:361-388 
24. Mucci A, Merlotti E, Üçok A, Aleman A \& Galderisi S: Primary and persistent negative symptoms: Concepts, assessments and neurobiological bases. Schizophr Res 2017; 186:19-28

25. Newcomer JW, Faustman WO, Yeh W, Csernansky JG: Distinguishing depression and negative symptoms in unmedicated patients with schizophrenia. Psychiatry Res 1990; 31:243-50

26. [0]Palumbo C, Volpe U, Matanov A, Priebe $S \&$ Giacco D: Social networks of patients with psychosis: a systematic review. BMC Res Notes 2015; 8:560-71

27. Provencher HL \& Mueser KT: Positive and negative symptom behaviors and caregiver burden in the relatives of persons with schizophrenia. Schizophr Res 1997; 26:71-80

28. Redmond $C$, Larkin $M$ \& Harrop C: The personal meaning of romantic relationships for ypung people with psychosis. Clin Child Psychol P 2010; 15:151-70

29. Rekhi G, Ang MS, Yuen CKY, Ng WY \&Jimmy Lee J: Assessing negative symptoms in schizophrenia: Validity of the clinical assessment interview for negative symptoms in Singapore. Schizophr Res 2019; 206:177-82

30. Remington G, Foussias G, Fervaha G, Agid O, Takeuchi H, Lee J et al.: Treating Negative Symptoms in Schizophrenia: an Update. Curr Treat Options Psych 2016; 3:133-50

31. Richter J, Hesse K, Schreiber L, Burmeister CP, Eberle $M C$, Eckstein KN et al.: Evidence for two distinct domains of negative symptoms: Confirming the factorial structure of the CAINS. Psychiatry Res 2019; 271:693-701
32. Siegrist K, Millier A, Amri I, Aballéa $S$ \& Toumi M: Association between social contact frequency and negative symptoms, psychosocial functioning and quality of life in patients with schizophrenia. Psychiatry Res 2015; 230:860-66

33. Strauss G \& Gold JM: A Psychometric Comparison of the Clinical Assessment Interview for Negative Symptoms and the Brief Negative Symptom Scale. Schizophr Bull 2016; 42:1384-94

34. Strauss GP, Vertinski M, Vogel SJ, Ringdahl EN \& Allen D: Negative symptoms in bipolar disorder and schizophrenia: A psychometric evaluation of the brief negative symptom scale across diagnostic categories. Schizophr Res 2016; 170:285-89

35. Valiente-Gómez A, Mezquida G, Romaguera A, Vilardebò I, Andrés H, Granados B et al.: Validation of the Spanish version of the Clinical Assessment for Negative Symptoms (CAINS). Schizophr Res 2015; 166:104-9

36. Ventura J, Lukoff D, Neuchterlein KH, Liberman R, Green $M F$ \& Shaner A: BPRS version 4.0. Clinical Research Center for Schizophrenia and Psychiatric Rehabilitation, UCLA Department of Psychiatry and Biobehavioral Sciences, 1993

37. World Health Organization: International Statistical Classification of Diseases and Related Health Problems 10th Revision (ICD-10). 2016. Retrieved from https://icd.who.int/browse10/2016/en\#/V on 18.11.2019

\section{Correspondence:}

Biljana Blaževska Stoilkovska, PhD

Deaprtment of Psychology, Faculty of Philosophy,

Ss. Cyril in Methodius University in Skopje

blvd. Goce Delčev 9A, 1000 Skopje, R. North Macedonia

E-mail: biljanabs@fzf.ukim.edu.mk 